\title{
Killian-Jamieson diverticulum
}

\author{
Ashlesha Satish Udare • Prabath Kumar Mondel • \\ Padma Vikram Badhe
}

Published online: 1 May 2013

(C) Indian Society of Gastroenterology 2013

\begin{abstract}
A 52-year-old gentleman presented with suprasternal dysphagia and cough for 3 months. Double-contrast barium study (Fig. 1) revealed a small left-sided Killian-Jamieson diverticulum. These diverticula originate on the anterolateral wall of the proximal cervical esophagus in a gap inferior to the cricopharyngeus and lateral to the longitudinal muscle of the esophagus [1]. Differentiation from Zenker's diverticulum is based primarily on the radiographic findings. The opening of a Zenker's diverticulum is above the level of the cricopharyngeus, with the sac lying posterior to the cervical esophagus on lateral images and in the midline on frontal images. On the other hand, the opening of a KillianJamieson diverticulum is located just below the level of the cricopharyngeus with the sac lying lateral to the cervical esophagus on frontal images and overlapping the anterior wall of the cervical esophagus on lateral images [2]. An accurate anatomic delineation helps in surgical planning.
\end{abstract}

A. S. Udare $(\varangle) \cdot$ P. K. Mondel $\cdot$ P. V. Badhe Department of Radiology, Seth G S Medical College and K E M Hospital, Parel, Mumbai 400 012, India e-mail: ashleshaudare@gmail.com

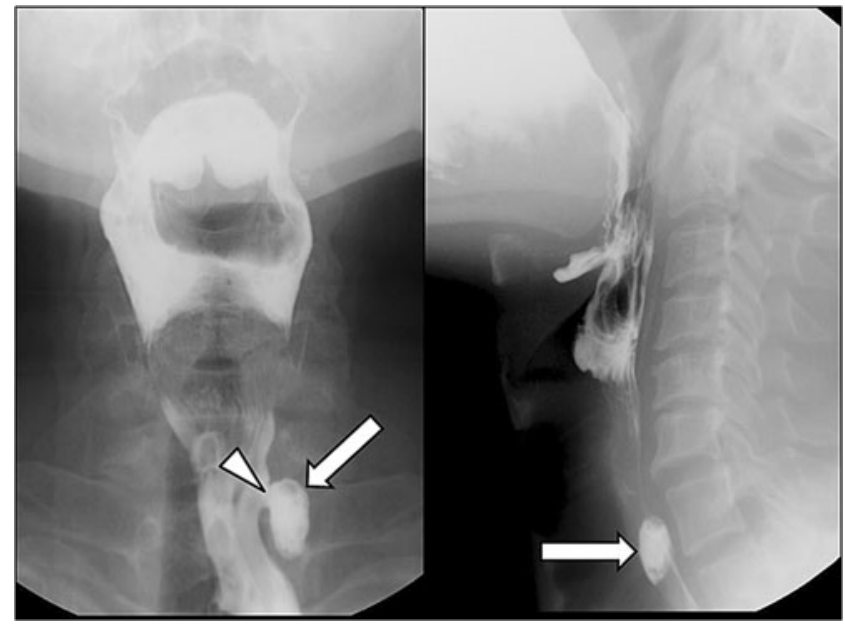

Fig. 1 Double-contrast barium pharyngoesophagram with patient in erect position: Spot radiographs obtained in frontal and lateral projections show a small left-sided Killian-Jamieson diverticulum (large white arrow) with a narrow neck (arrow head)

\section{References}

1. Ekberg O, Nylander G. Lateral diverticula from the pharyngoesophageal junction area. Radiology. 1983;146:117-22.

2. Rubesin SE, Levine MS. Killian-Jamieson diverticula: radiographic findings in 16 patients. AJR Am J Roentgenol. 2001;177:85-9. 